\title{
Determination of digestive proteolytic profile in the larvae of Dyspessa palidata (Staudinger) (Lepidoptera: Cossidae)
}

\author{
M. Mardani-Talaee, ${ }^{1}$ A. Zibaee ${ }^{2}$ \\ 'Department of Plant Protection, Faculty of Agricultural Sciences, University of Mohaghghegh \\ Ardabili; ${ }^{2}$ Department of Plant Protection, Faculty of Agricultural Sciences, University of Guilan, \\ Rasht, Iran
}

\begin{abstract}
Digestive proteolytic profile was determined in the larvae of Dyspessa palidata (Staudinger), which is the most important pest of Alliaceae in Europe and Iran. Compartmentalisation of the proteolytic activities by considering soluble and membrane-bound fractions revealed that soluble fractions of the whole midgut preparations had higher general proteolytic activity than membrane-bound fractions. Also, four proteolytic bands were observed in the soluble fraction of the total midgut preparation in electrophoresis. Compartmentalisation of the specific proteases revealed presence of trypsin, elastase, aminoand carboxy peptidases in posterior midgut but the highest activities of other proteases were found in anterior midgut. The highest activity of general protease was found at pHs of 6 and 8. Also, $\mathrm{pH}$ dependency of trypsin, chymotrypsin and elastase were found at values of 8, 7-8 and 9 but cathepsins had the optimal $\mathrm{pH}$ at 6 . Exopeptidases showed the optimal value at $\mathrm{pH}$ of 7 although carboxypeptidase showed same activity at values of 6 and 7 . The inhibitory concentrations $50 \%\left(\mathrm{IC}_{50}\right)$ of AEBSF.HCL on trypsin, chymotrypsin and elastase proteases were found to be $3.69,3.31$ and $4.09 \mathrm{mM}$, respectively. $\mathrm{IC}_{50}$ concentrations of TLCK, SBTI and TPCK significantly inhibited trypsin and chymotrypsin activities. $\mathrm{IC}_{50}$ of E-64 were 3.67 and $4.16 \mathrm{mM}$ on cathepsin $\mathrm{B}$ and $\mathrm{L}$ but cystatin revealed 5.22 and $4.48 \mathrm{mM}$ concentrations on cathepsin B and L, respectively. EDTA and phenathroline as metalloproteinase inhibitors had $\mathrm{IC}_{50}$ of 3.25 and $3.91 \mathrm{mM}$ on general proteolytic activity.
\end{abstract}

\footnotetext{
Correspondence: Arash Zibaee, Department of Plant Protection, Faculty of Agricultural Sciences, University of Guilan, Rasht, Iran.

Tel.: +98.0131.6690284 - Fax: +98.0131.6690281.

E-mail: Arash.zibaee@gmx.com ; arash.zibaee@guilan.ac.ir

Key words: Digestive protease; Dyspessa palidata; characterisation.

Received for publication: 25 May 2015.

Revision received: 27 June 2015.

Accepted for publication: 27 June 2015.

(C) Copyright M. Mardani-Talaee and A. Zibaee, 2015

Licensee PAGEPress, Italy

Journal of Entomological and Acarological Research 2015; 47:5285

doi:10.4081/jear.2015.5285
}

This article is distributed under the terms of the Creative Commons Attribution Noncommercial License (by-nc 3.0) which permits any noncommercial use, distribution, and reproduction in any medium, provided the original author(s) and source are credited.
Results of the current study revealed larvae of $D$. palidata utilised different proteases to increase digestive efficiency when they fed on the host plants containing several toxic molecules.

\section{Introduction}

Dyspessa palidata (Staudinger) (Lepidoptera: Cossidae) is the most important pest of the Alliaceae family in Europe and Iran and causes severe damages in both fields and stores (Khanjani, 2005). Larvae penetrate bulbs of Allium spp. and the inner parts of garlic, facilitating spoilage by pathogens (Haydari, 1986). The moth overwinters as $5^{\text {th }}$ instar larvae and pupates in soil. Major control procedures against the pest are using light and pheromone traps, crop rotation, sanitation and disinfection in stores (Khanjani, 2005).

Proteases are one of the key enzymes involved in several physiological processes in insects from digestion to cell death (Kanost \& Clem, 2012; Terra \& Ferreira, 2012). In protein digestion, proteinases (endopeptidases) initially attack internal bonds, converting the macromolecules to oligopeptides. Then, amino- (EC 3.4.11.2) and carboxypeptidases (EC 3.4.17.1), remove amino acids from $\mathrm{N}$ - and C-terminals (Terra \& Ferreira, 2012). Proteinases are categorised into several subclasses based on their chemical groups regarding catalysis and substrate specificity (Kanost \& Clem, 2012). Serine, cysteine, aspartic and metalloproteinases are the four main groups of endopeptidases. Serines have serine, histidine, and aspartic acid residues in their active site divided into trypsin (EC 3.4.21.4), chymotrypsin (EC 3.4.21.1) and elastase (EC 3.4.21.36) proteases are associated with different substrate specificities (Terra \& Ferreira, 2012). These enzymes hydrolyse a peptide bond by the hydroxyl group in the side chain of serine residue that acts as a nucleophile (Kanost \& Clem, 2012). Cathepsins have two main groups namely B (EC 3.4.22.1) and L (EC 3.4.22.15) that the sulfhydryl group of a cysteine side chain acts as nucleophile to hydrolyse peptide bonds (Terra \& Ferreira, 2012; Kanost \& Clem, 2012). Cathepsin D (EC 3.4.23) is a member of aspartic proteinases containing water molecule in the active site as the nucleophile similar metalloproteinases (Kanost \& Clem, 2012). Many insects use different types of proteases based on various food sources. Also, these enzymes may be involved to inactivate toxic compounds ingested along with food (Terra \& Ferreira, 2012).

Evidence of serines in Lepidoptera, cathepsins in Hemiptera and Coleoptera, and exopeptidases in almost all insects has been determined several studies on digestive proteases of insects (Terra \& Ferreira, 1994; Johnson \& Rabosky, 2000; Cristofoletti et al., 2003; Terra $\&$ Ferreira, 2012). Determination of such enzymes is crucial to target them as a pest control procedures. Pest control tactics utilising protease inhibitors, lectins and ribosome inactivating proteins require our 
understanding of insect interactions by the given entomotoxic molecules. In Lepidoptera, a majority of the studies have been done on models where the larvae fed on aboveground parts of host plants. In the current study, we wanted to determine the digestive proteolytic profile in the midgut of $D$. palidata larvae, which intensively fed on Allium spp. bulbs. This study is important because bulbs of garlic are rich of lectins and protease inhibitors (Ankri \& Mirelman, 1999; Clement et al., 2010). Therefore, determination of protease presence is needed to find possible adaptations among secondary components of garlic and proteases when this is a first report on the digestive physiology of $D$. palidata. Initially, compartmentalisation of the proteolytic activities was determined in the anterior and posterior midguts by considering soluble and membrane bound fractions. Finally, the experiment was continued to find optimal $\mathrm{pH}$ and proteolytic nature in presence of specific inhibitors.

\section{Materials and methods}

\section{Insect rearing}

The stock culture of $D$. pallidata was obtained from a laboratory colony reared on garlic bulbs (Hamedan cultivar) in small plastic tubes (diameter $2 \mathrm{~cm}$, depth $5 \mathrm{~cm}$ ). Larvae of $D$. pallidata were reared on the bulbs in a growth chamber (Binder KBWF, model 240, Germany) at $25 \pm 1^{\circ} \mathrm{C}, 65 \pm 5 \%$ relative humidity, and complete darkness to reach $5^{\text {th }}$ instar larvae.

\section{Sample preparation}

Larvae of $D$. palidata were randomly selected and their midguts were removed by dissection in ice-cold saline solution $(\mathrm{NaCl}, 125 \mathrm{mM})$. Samples including total, anterior- and posterior-midguts were homogenised by a glass pestle in ice-cold distilled water and centrifuged at 28,500 $\mathrm{g}$ for $20 \mathrm{~min}$ (Elpidina et al., 2001). Supernatant was considered as the soluble fraction and the amount of protein was determined based on Lowry et al. (1951). Pellets from first centrifugation were used in solubilising the membrane-bound enzymes in Triton X100 , membrane preparations for $20 \mathrm{~h}$ at $40^{\circ} \mathrm{C}$, in a ratio of $10 \mathrm{mg}$ of Triton X-100 per mg of protein. Incubated samples were centrifuged at $28,500 \mathrm{~g}$ rpm for $30 \mathrm{~min}$ and gained supernatant was used as membrane-bound fraction (Ferreira \& Terra, 1983).

\section{Compartmentalisation of proteolytic activity}

In all prepared samples, general and proteolytic activities were assayed using specific substrates, negative control (Pre-boiled samples for $30 \mathrm{~min}$ ) and the highest recommended of specific inhibitors besides visualisation of the enzymes in native-polyacrylamide electrophoresis (See below).

\section{General proteolytic assay}

General proteolytic activity was measured using haemoglobin (20 $\mathrm{mg} / \mathrm{mL}$ ) based on a method described by Elpidina et al. (2001). The reaction mixture consisted of $100 \mu \mathrm{L}$ of universal buffer (glycine, succinate, 2-morpholinoethan sulphuric acid, $20 \mathrm{mM}$ ), 40- $\mu \mathrm{L}$ haemoglobin and $20 \mu \mathrm{L}$ of the samples. After incubation at $37^{\circ} \mathrm{C}$ for $60 \mathrm{~min}$, proteolysis was stopped by the addition of $150 \mu \mathrm{L}$ of $10 \%$ trichloroacetic acid. Precipitation was achieved by cooling at $4^{\circ} \mathrm{C}$ for $120 \mathrm{~min}$ and centrifuged at $20,000 \mathrm{~g}$ for $10 \mathrm{~min}$. An equal volume of $\mathrm{NaOH}(2 \mathrm{M})$ was added to the supernatant and absorbance was recorded at $440 \mathrm{~nm}$. The blank consisted of all mentioned portions except for enzyme solution.

\section{Serine proteolytic assay}

Trypsin-, chymotrypsin-, and elastase-like activities were assayed using 1 mM BApNA (Na-benzoyl-L-arginine-p-nitroanilide; Sigma-
Aldrich, 19362), SAAPPpNA (N-succinyl-alanine-alanine-prolinephenylalanine-p-nitroanilide, Sigma-Aldrich, S7388), and SAAApNA (N-succinyl-alanine-alanine-alanine-p-nitroanilide; Sigma-Aldrich, S4760) as substrates, respectively. The reaction mixture consisted 30 $\mu \mathrm{L}$ of universal buffer ( $\mathrm{pH} 8), 5 \mu \mathrm{L}$ of each of the substrates, and $5 \mu \mathrm{L}$ of enzyme solution. The reaction mixture was incubated for $10 \mathrm{~min}$ and the absorbance was measured at $405 \mathrm{~nm}$ by $p$-nitroaniline release. To determine the specific proteolytic activity, a negative control was separately provided for each substrate containing all the mentioned components with the enzyme pre-boiled at $100^{\circ} \mathrm{C}$ for $30 \mathrm{~min}$. Also, inhibition tests were done using AEBSF.HCl [4-(2-Aminoethyl) benzenesulfonyl fluroride hydrochloride; Thermo Scientific, USA, 78431] (2 mM; Walsmann et al., 1972), TLCK [N -p-Tosyl-L-lysine methyl ester hydrochloride, Sigma-Aldrich, T5012] (1 mM; Shaw et al., 1965), TPCK [N-tosyl-Lphenylalanine chloromethyl ketone; Sigma-Aldrich, T7254) (1 mM; Hahm et al., 1995).

\section{Cysteine proteinase assay}

Cathepsin B and L activities were evaluated using a $1 \mathrm{mM}$ concentration of Z-Ala-Arg- Arg 4-methoxy--naphthylamide acetate and Nbenzoyl-Phe-Val-Arg-pnitroanilide hydrochloride (C8536, SigmaAldrich, B2133) as substrates, respectively. The reaction mixture consisted of $30 \mu \mathrm{L}$ universal buffer ( $\mathrm{pH} 5$ ), $5 \mu \mathrm{L}$ of each substrate, and 5 $\mu \mathrm{L}$ of the enzyme solution. The reaction mixture was incubated for 10 min prior to read absorbance at $405 \mathrm{~nm}$. Also, inhibition tests were done using E-64 [E-(L-transepoxysuccinyl-leucylamido (4-guanidino)butane; Sigma-Aldrich, E3132)] (0.01 mM; Hamada et al., 1981).

\section{Exopeptidases}

Activities of amino- and carboxypeptidases were assayed using hippuryl-L-arginine (Sigma-Aldrich, H2508) and hippuryl-L-phenylalanine (Sigma-Aldrich, H6875), respectively. The reaction mixture consisted of $30 \mu \mathrm{L}$ of universal buffer ( $\mathrm{pH} 7$ as the recommended $\mathrm{pH}$ for exopeptidases), $5 \mu \mathrm{L}$ of each substrate, and $5 \mu \mathrm{L}$ of enzyme solution. The reaction mixture was incubated for $10 \mathrm{~min}$ and read at $340 \mathrm{~nm}$.

\section{Effect of $\mathrm{pH}$ on general and specific proteolytic activities}

Ranges of 4-12 were considered to find optimal pH of general and specific proteolytic activities in the larval midgut of $D$. palidata. Universal buffer was used in this experiment and all steps were done as described earlier.

\section{Effects of specific inhibitors on proteolytic activity}

Concentrations of several inhibitors were prepared and exposed to find activity of their target proteases. These inhibitors and their used concentrations were: AEBSF.HCl $(0.1,0.3,0.5 .1$ and $2 \mathrm{mM})$ for serine, TLCK $(0.1,0.3,0.5 .1$ and $2 \mathrm{mM})$ and SBTI $(0.1,0.3,0.5 .1$ and $2 \mathrm{mM})$ for trypsin, TPCK $(0.1,0.3,0.5 .1$ and $2 \mathrm{mM})$ for chymotrypsin, E-64 $(0.1,0.3,0.5,0.7$ and $1 \mathrm{mM})$ and cystatin $(0.1,0.3,0.5,1$ and $3 \mathrm{mM})$ for cathepsins, EDTA and phenanthroline $(0.1,0.5,1,3$ and $5 \mathrm{mM})$ as metalloproteinase inhibitors. Reaction mixtures contained $50 \mu \mathrm{L}$ of universal buffer in optimal value, $20 \mu \mathrm{L}$ of specific substrate, $20 \mu \mathrm{L}$ of inhibitors and $10 \mu \mathrm{L}$ of enzyme. Incubation time was $10 \mathrm{~min}$ and absorbance was read at the given wavelength.

\section{Native-polyacrylamide gel electrophoresis}

Zymogram analysis was carried out finding presence of proteolytic isozymes by non-denaturing polyacrylamide gel electrophoresis (PAGE) described by Laemmli (1970). Native-PAGE was performed in a $10 \%$ (w/v) separating gel and a $4 \%$ stacking gel. The electrode buffer was prepared based on the method of Laemmli (1970). The sample buffer contained $25 \%$ stacking buffer ( $0.5 \mathrm{M} / \mathrm{L}$ Tris-HCl [pH 6.8]), 20\% glycerol, and $0.005 \%$ (w/v) bromophenol blue. Electrophoresis was conduct- 
ed at room temperature under voltage $(100 \mathrm{~V})$ until the blue dye reached the bottom of the slab gel. Electrophoretic detection of proteolytic enzymes was performed according to the method described by Garcia-Carreno et al. (1993). Non-reducing SDS-PAGE was carried out at $4^{\circ} \mathrm{C}$ in gels containing $0.5 \%$ gelatin. When the dye reached the end of the glass, the gel was gently removed, washed with distilled water and immediately fixed and stained overnight with $0.1 \%$ of Coomassie brilliant blue R-250 in methanol-acetic acid-water (50:10:40). De-staining was done in methanol-acetic acid-water (50:10:40).

\section{Protein assay}

Protein concentrations were assayed according to the method described by Lowry et al. (1951) provided by Ziest Chem. Co., Tehran-Iran.

\section{Statistical analysis}

Data were compared by one-way analysis of variance (ANOVA) followed by Tukey's test $(\mathrm{P} \leq 0.05)$. When inhibitors were used in compartmentalisation, $\mathrm{t}$-tests were used to find statistical differences between control and inhibitor treatments. Differences between samplings were considered statistically significant at a probability less than $5 \%$.

\section{Results}

\section{Compartmentalisation of general proteolytic activity}

Compartmentalisation of the general proteolytic activity in the larvae of $D$. palidata is shown in Figure 1. Overall, the proteolytic activities in the soluble fractions were higher than those of membrane-bound. Moreover, total midgut preparation showed the highest proteolytic activity versus anterior- and posterior-midgut preparations $(\mathrm{P} \leq 0.0001$, Pr>F: 168.68). In gel electrophoresis, four proteolytic bands were observed in the soluble total midgut but these bands were not present in other preparations. The gel shows almost no proteolytic band in membrane-bound fractions (Figure 1).

\section{Compartmentalisation of specific proteolytic activity}

Both a negative control and specific inhibitors were used to show distribution of specific proteases in total, anterior- and posteriormidgut preparations (Figures 2-4). Although activities of all serine proteases were observed in the larval midgut of $D$. palidata, trypsin $(\mathrm{P} \leq 0.002$, t-test $)$ and elastase $(\mathrm{P} \leq 0.013$, t-test) showed higher activity in the anterior-midgut but it was vice versa in the case of chymotrypsin ( $\mathrm{P} \leq 0.003$, t-test) (Figure 2).

Both cathepsin $\mathrm{B}(\mathrm{P} \leq 0.003$, t-test $)$ and $\mathrm{L}(\mathrm{P} \leq 0.030$, t-test $)$ showed the highest activities in anterior-midgut but posterior-midgut had the highest activities of exopeptidases ( $\mathrm{P} \leq 0.0012$ and $\mathrm{P} \leq 0.0003$ Tukey test) (Figures 3 and 4). In all above-mentioned treatments, the highest concentration of specific inhibitors significantly decreased proteolytic activities (Figures 2-4).

\section{Effect of $\mathrm{pH}$ on general and specific proteolytic activities}

The optimal $\mathrm{pH}$ values of whole midgut preparation varied from 6-8 $(\mathrm{P} \leq 0.0005, \mathrm{Pr}>\mathrm{F}: 57.26)$ but optimal $\mathrm{pH}$ of 6 and 8 were observed when the experiment was done by anterior- $(\mathrm{P} \leq 0.0001, \mathrm{Pr}>\mathrm{F}$ : 134.97) and posterior-midgut preparations ( $\mathrm{P} \leq 0.0001, \mathrm{Pr}>\mathrm{F}$ : 56.47) (Figure 5). $\mathrm{pH}$ of 8, 7-8 and 9 were optimal values for tryspin ( $\mathrm{P} \leq 0.0001, \operatorname{Pr}>\mathrm{F}: 55.01)$, chymotrypsin $(\mathrm{P} \leq 0.0001, \mathrm{Pr}>\mathrm{F}$ : 109.57) and elastase $(\mathrm{P} \leq 0.0001, \mathrm{Pr}>\mathrm{F}$ : 20.15) activities, respectively (Figure 6). In cathepsins, optimal pH was $6(\mathrm{P} \leq 0.0001, \operatorname{Pr}>\mathrm{F}: 83.57 ; \mathrm{P} \leq 0.0001, \operatorname{Pr}>\mathrm{F}: 72.22)$ (Figure 6). Although the highest activity of aminopeptidase was observed at $\mathrm{pH}$ of 6 $(\mathrm{P} \leq 0.0001$, Pr $>\mathrm{F}: 162.75)$, carboxypeptidase showed the highest activities in both $\mathrm{pH}$ values of 6 and 7 ( $\mathrm{P} \leq 0.0001, \operatorname{Pr}>\mathrm{F}$ : 68.53) (Figure 6).

\section{Effects of specific inhibitors on proteolytic activity}

Specific inhibitors used in this experiment significantly inhibited proteolytic activities in the larval midgut of $D$. palidata (Figure 7). AEBSF.HCl inhibited all serine protease activities between 70 to $90 \%$ by the inhibitory concentrations $50 \%\left(\mathrm{IC}_{50}\right)$ concentrations of $3.69,3.31$ and $4.09 \mathrm{mM}$ on trypsin, chymotrypsin and elastase, respectively (Figure 7A). Both TLCK and SBTI are the specific inhibitors of tryspins but those inhibited up to $80 \%$ of the enzymatic activity by $\mathrm{IC}_{50}$ concentrations of 3.34 and $3.96 \mathrm{mM}$, respectively (Figure 7B). Also, TPCK lead to $70 \%$ of chymotrypsin inhibition by $\mathrm{IC}_{50}$ concentration of $4.35 \mathrm{mM}$ (Figure 7B). E-64 caused almost $80 \%$ of inhibition on cathepsins B and $\mathrm{L}$ by $\mathrm{IC}_{50}$ of 3.67 and $4.16 \mathrm{mM}$ (Figure 7C) but cystatin revealed $\mathrm{IC}_{50}$ of 5.22 and $4.48 \mathrm{mM}$ on cathepsin, respectively. Finally, EDTA and phananthroline revealed inhibition of 70 and $80 \%$ as inhibitors of metalloproteinases, respectively on general proteolytic activity by $\mathrm{IC}_{50}$ of 3.25 and 3.91 , respectively (Figure 7E).

\section{Discussion}

The current study demonstrated proteolytic profile and compartmentalisation in the larval midgut of $D$. palidata. Our results revealed higher activity of proteases in soluble fraction than membrane-bound
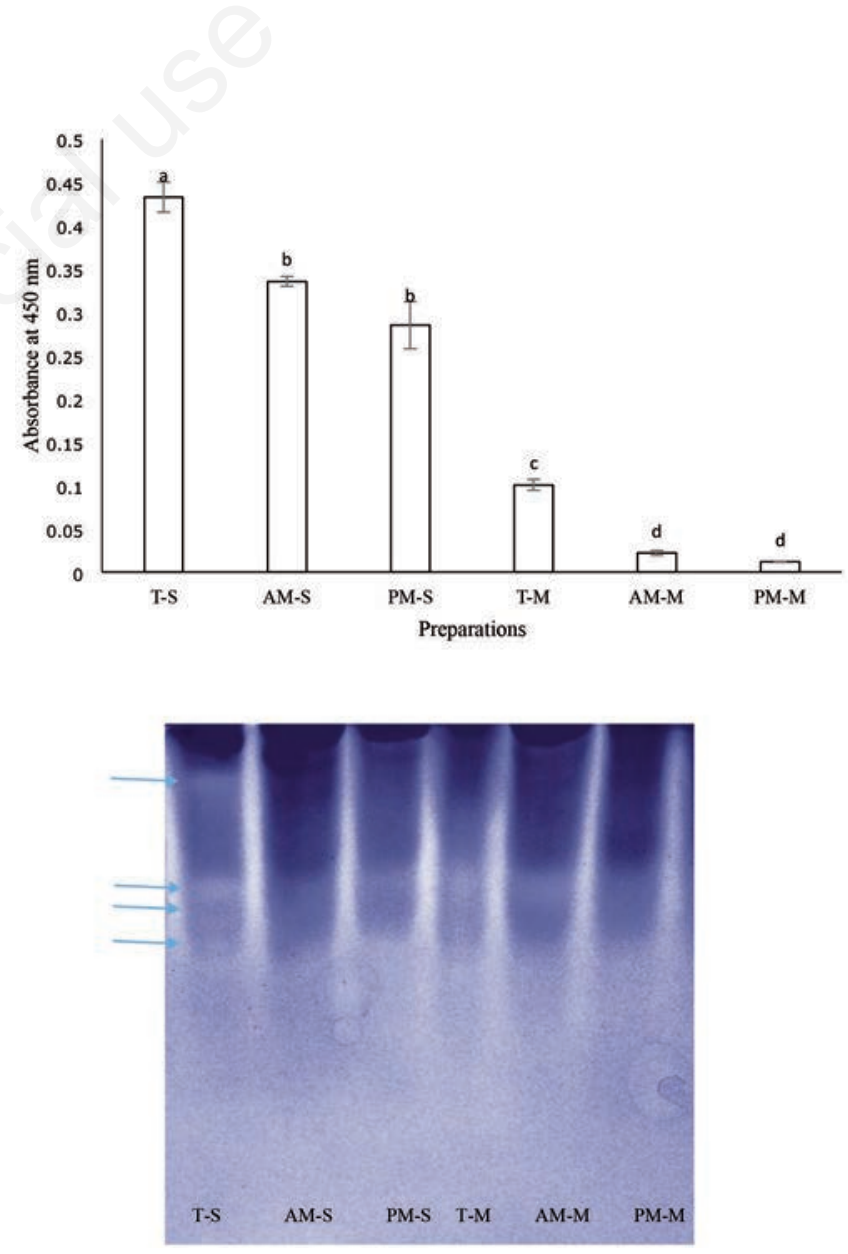

Figure 1. General proteolytic activity in different parts of the larval midgut from $D$. palidata. Statistical differences have been marked by various letters (Tukey test, $\mathrm{P} \leq \mathbf{0 . 0 5}$ ). T-S, total soluble; AM-S, anterior midgut soluble; PM-S, posterior midgut soluble; T-M, total membrane-bound; AM-M, anterior midgut membrane-bound; PM-M, posterior midgut membrane-bound. 
one. It should be considered that the higher activity in anterior/posterior midgut in comparison with total preparation might be due to concentration of protein used to calculate specific activity. Absorbance of the reaction mixture in total midgut preparation was higher than those of separated midgut preparations. These differences point out digestion organisation in the larvae of $D$. palidata. Elpidina et al. (2001) reported higher proteolytic activity in the posterior midgut of Nauphoeta cinerea Oliv. (Blattoptera: Blaberidae). Zibaee (2012) reported higher proteolytic activities in the soluble fraction of the larval midgut in Pieris brassicae L. (Lepidoptera: Pieridae) except for amino and carboxypeptidases. Ajamhassani $e t$ al. (2012) and Yazdani et al. (2013) showed that all digestive proteases in the larvae of Utethesia pulchella L. (Lepidoptera: Arctiidae) and Papilio demoleus L. (Lepidoptera: Papilionidae) were active in soluble fraction. These differences could be attributed to feeding behaviours of these species. First, a regulated release of digestive enzymes has been reported in the lumen of midgut via stored vesicles in the cyto-
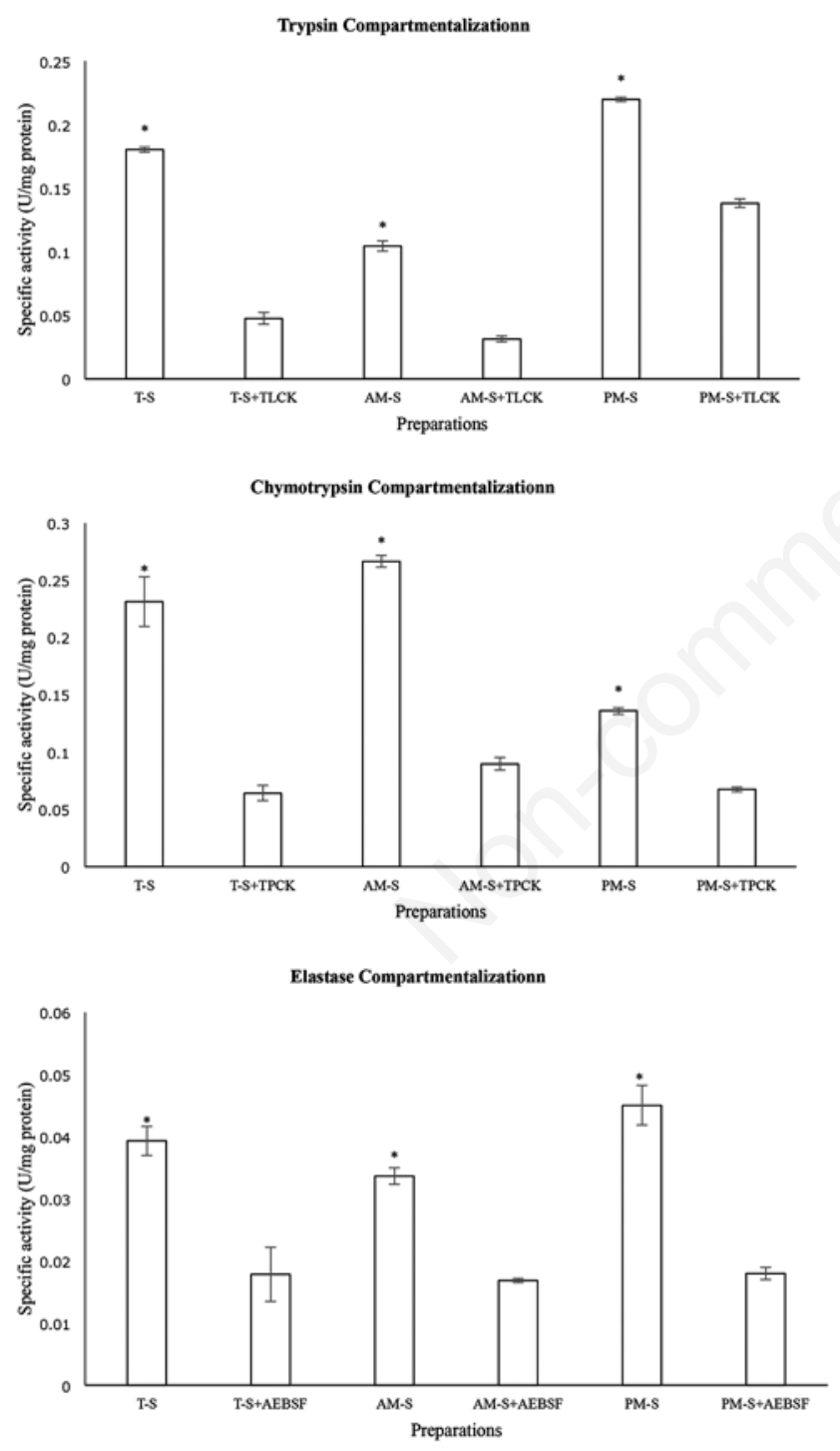

Figure 2. Serine protease activities in different parts of the larval midgut from $D$. palidata. Statistical differences have been marked by asterisks between each enzymatic activity in each part versus inhibitor $(t-t e s t, P \leq 0.05)$. T-S, total soluble; $A M-S$, anterior midgut soluble; PM-S, posterior midgut soluble. plasm (Lehane et al., 1996). On the other hand, a trace of enzymatic activity might be detected in the midgut of insects even in starvation. Woodring et al. (2009) reported a continuous secretion of trypsin and aminopeptidase at a basal rate in unfed individuals of Gryllus bimaculatus (Orthoptera: Gryllidae). Second, Terra \& Ferreira (2012) proposed the occurrence of membrane-bound exopeptidases in the midgut of Lepidoptera, Coleoptera and Diptera as the receptors of Cry proteins and lectins. We suppose a phenomenon similar to the second scenario in case of $D$. palidata larvae. The larvae utilise garlic bulbs, which have rich sources of lectins (Clement et al., 2010). Lectins are the heterogenous proteins that bind to some receptors on the membrane of midgut epithelial cells cause cytotoxicity and disrupt digestion processes in insects. So, if the larvae of $D$. plidata have membrane-bound enzymes, mainly exopeptidases, those may be targeted by garlic lectins and adversely affect the digestion physiology of the larvae. Hence, the majority of digestive proteases of the larvae are soluble rather than membrane-bound. Moreover, suggestion of Terra \& Ferreira (2012) may not be common for all insects since our previous studies on the larvae of $U$. pulchella, P. demoleus and Bacterocera oleae Gmelin (Diptera: Tephritidae) showed the soluble nature of digestive proteases (Ajamhassani et al., 2012; Yazdani et al., 2013; Delkash-Roudsari et al., 2014). In addition, different assayed proteases had various activities in the anterior- and posterior-midgut preparations. Higher activity of cathepsins and chymotrypsin in anteriormidgut of $D$. palidata larvae may be attributed to importance of cathepsins in digestion or hydrolysing of toxic molecules ingested along with food. This may show an evolutionary phenomenon in the larvae that some proteins (nutrient or toxic) must be digested earlier than others and these two series of proteases are the initial choice to
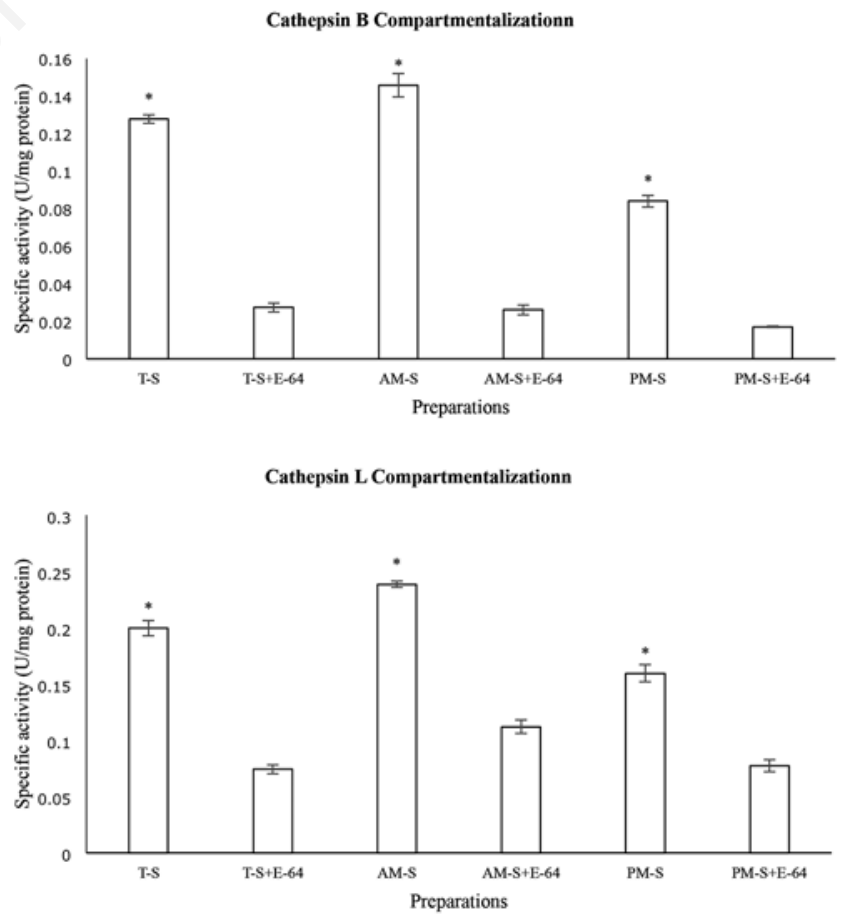

Figure 3. Cathepsin protease activities in different parts of the larval midgut from $D$. palidata. Statistical differences have been marked by asterisks between each enzymatic activity in each part versus inhibitor $(t-t e s t, P \leq 0.05)$. T-S, total soluble; AM-S, anterior midgut soluble; PM-S, posterior midgut soluble. E-64 refers to specific inhibitor of cathepsins. 
do so. It is notable that this conclusion must be further studied by feeding assay and molecular analysis.

Determination of $\mathrm{pH}$ profile in the total midgut preparation showed a range of values from 6-8 with optimal $\mathrm{pH}$ for general proteolytic activities at $\mathrm{pH} 6$ and 8 for anterior- and posterior-midgut, respectively. Moreover, serine had optimal $\mathrm{pH}$ of 7-8, cathepsisn at $\mathrm{pH} 6$ and exopeptidases $\mathrm{pH}$ 6-7. Different $\mathrm{pH}$ sets in the midgut of insects have been demonstrated in several cockroaches (Elpidina et al., 2009). Studies made by Zibaee (2012) and Yazdani et al. (2013) revealed two pH sets of proteolytic activities in the larvae of $P$. brassicae and $P$. demoleus. These differences reflect presence of different proteases in the midgut fractions. In our case, acidic $\mathrm{pH}$ of anterior-midgut indicates presence of cathepsins although another peak was observed at $\mathrm{pH} 8$, referring to chymotrypsin. In the posterior-midgut, the optimal value of $\mathrm{pH} 8$ may reflect the presence of trypsin and elastase. Dependency of the specific proteases on $\mathrm{pH}$ were as expected based on the category of each enzyme. Although there are usually some differences in optimal $\mathrm{pH}$ of specific proteases between different insects, the $\mathrm{pH}$ ranges of serines, cathepsins and exopeptidases are alkali, acidic and acidic/neutral, respectively. These differences are expected since insects feed on various food sources, which contain different proteins and potential toxic components. Since $\mathrm{pH}$ is one of the crucial factors affecting biochemical reactions, several optimal pHs might indicate the adaptability of the enzymes to be able to hydrolyse food substrates.

In the inhibition study, different concentrations of several specific inhibitors were prepared and exposed to digestive proteases of $D$. palidata larvae using given substrates. AEBSF.HCl inhibited tryspin, chymotrypsin and elastase activities by the highest and the lowest inhibition on chymotrypsin and elastase, respectively. Moreover, the inhibitions between 70 and $90 \%$ were observed using TLCK and SBTI as specific inhibitors of trypsin and TPCK as specific inhibitor of chymotrypsin. Different concentrations of E-64 also decreased activities of cathepsins $\mathrm{B}$ and $\mathrm{L}$ in addition to the presence of metalloproteinases in the midgut of $D$. palidata. This may be due to decreased activity of the general protease using EDTA and

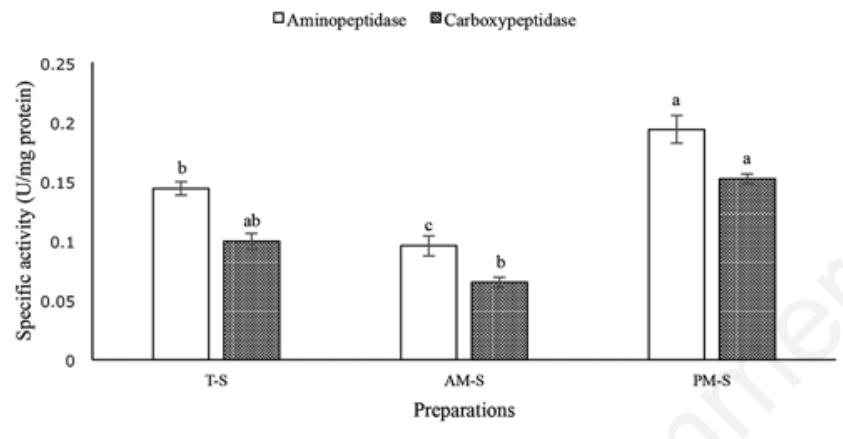

Figure 4. Exopeptidase activities in different parts of the larval midgut from $D$. palidata. Statistical differences have been marked by various letter among prepared sections (Tukey test, P $\leq$ 0.05). T-S; total soluble, AM-S; anterior midgut soluble; PM$S$, posterior midgut soluble.

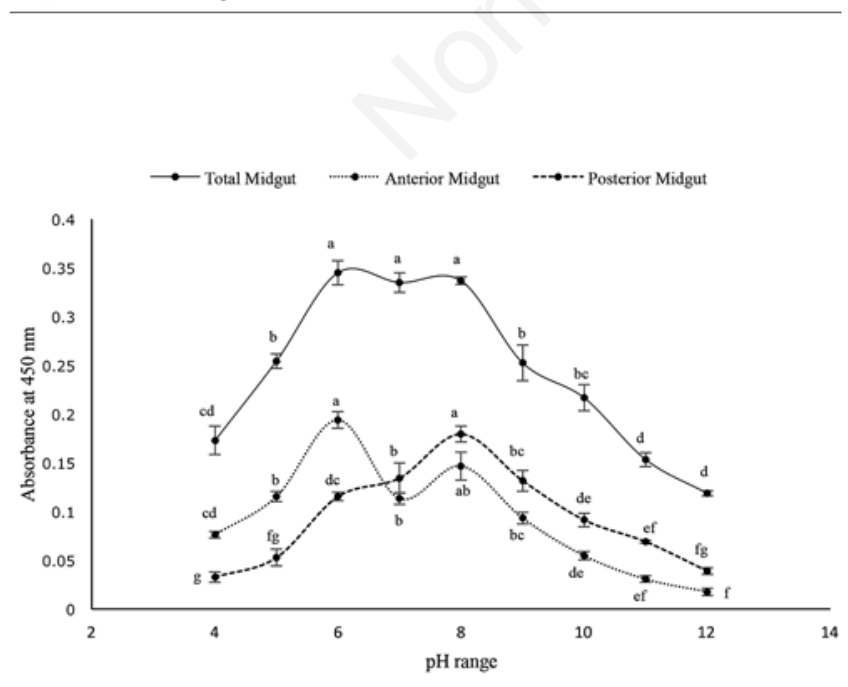

Figure 5. Optimal $\mathrm{pH}$ of general proteolytic activity in different parts of the larval midgut from $D$. palidata. Statistical differences have been marked by various letter among prepared sections (Tukey test, $\mathbf{P} \leq \mathbf{0 . 0 5}$ ).
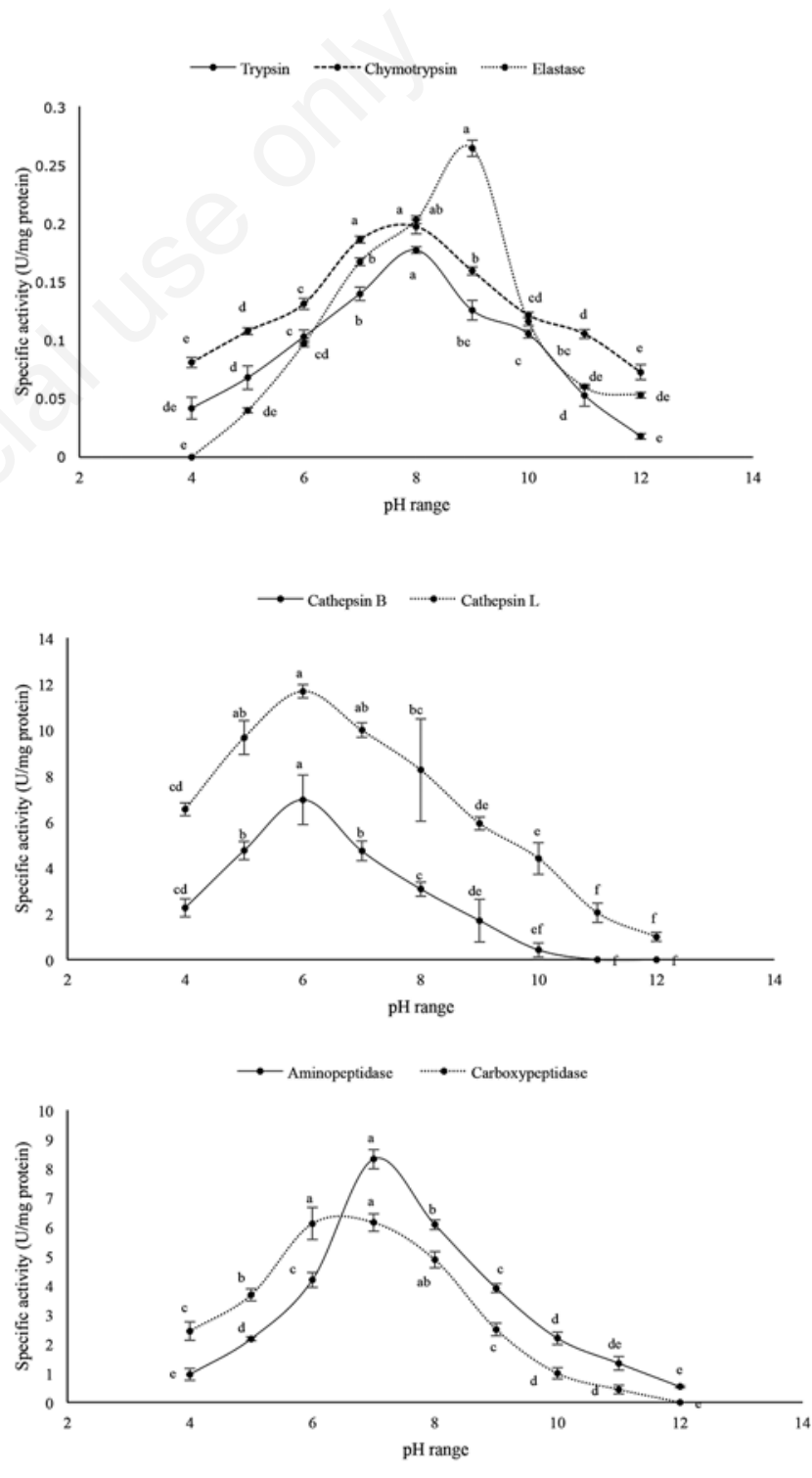

Figure 6. $\mathrm{pH}$ dependency in the larval serine, cathepsins and exopeptidases from $D$. palidata. Statistical differences have been marked by various letter among prepared sections (Tukey test, $\mathbf{P} \leq \mathbf{0 . 0 5 )}$. 
phenanthroline. The given results corresponded to the hydrolysis of used synthetic substrates in negative control experiments supporting the presence of these proteases in $D$. palidata. In a majority of similar studies, presence of serine proteinases has been reported but either no or trace activities of cathepsins have been found. In P. demoleus, activity of serines and cathepsins has been shown using synthetic substrates and specific inhibitors (Yazdani et al., 2013). Moreover, no activity of cathepsins have been determined in the larvae of Ectomyelois ceratoniae Zeller (Lepidoptera: Pyralidae) but these enzymes show trace activities followed by feeding on $2 \%$ concentration of Citrullus colocynthis L agglutinin (Ranjbar et al., 2011). We believe that these enzymes are secreted in the response of plant's secondary metabolites, which have entomotoxic effects on insects. This statement must be further supported by feeding assays and gene expression studies. Moreover, Saikia et al. (2010) found no cathepsin activity in the midgut of Antheraea assamensis (Helfer) (Lepidoptera: Saturniidae) but caseinolytic activity in the midgut preparation decreased using E-64. This finding was different if the larvae fed on different host plants. The authors indicated the ability of E-64 to reversible inhibition of serine proteases of $A$. assamensis. Although this mechanism may occur in $D$. palidata but cystatin led to 50 and $70 \%$ inhibition that requires further investigation.

Results of this study determined the compartmentalisation of digestive proteases in different parts of the larval midgut in $D$. palidata. While a majority of the general and specific proteolytic activities were observed in soluble fraction, their distribution was different in anterior- and posterior-midgut. Moreover, activity of serine and cathepsin proteases were shown using synthetic substrates and specific inhibitors. Determination of proteolytic profiles on pest insects like $D$. palidata is worthwhile to better understand protein digestion in food sources that contain inhibitors. Oppert (2000) reviewed and explained adaptive responses of insects after ingestion of proteinase inhibitors by compensatory mechanisms that are important to better understand inhibitor-based strategies for L. Knowledge on insect-inhibitor interactions are of interest because plant breeding programs are designed to provide resistant host plants expressing toxic molecules mainly inhibitors. So, potential ability of insect compensatory mechanism must be elucidated to prevent possible negative
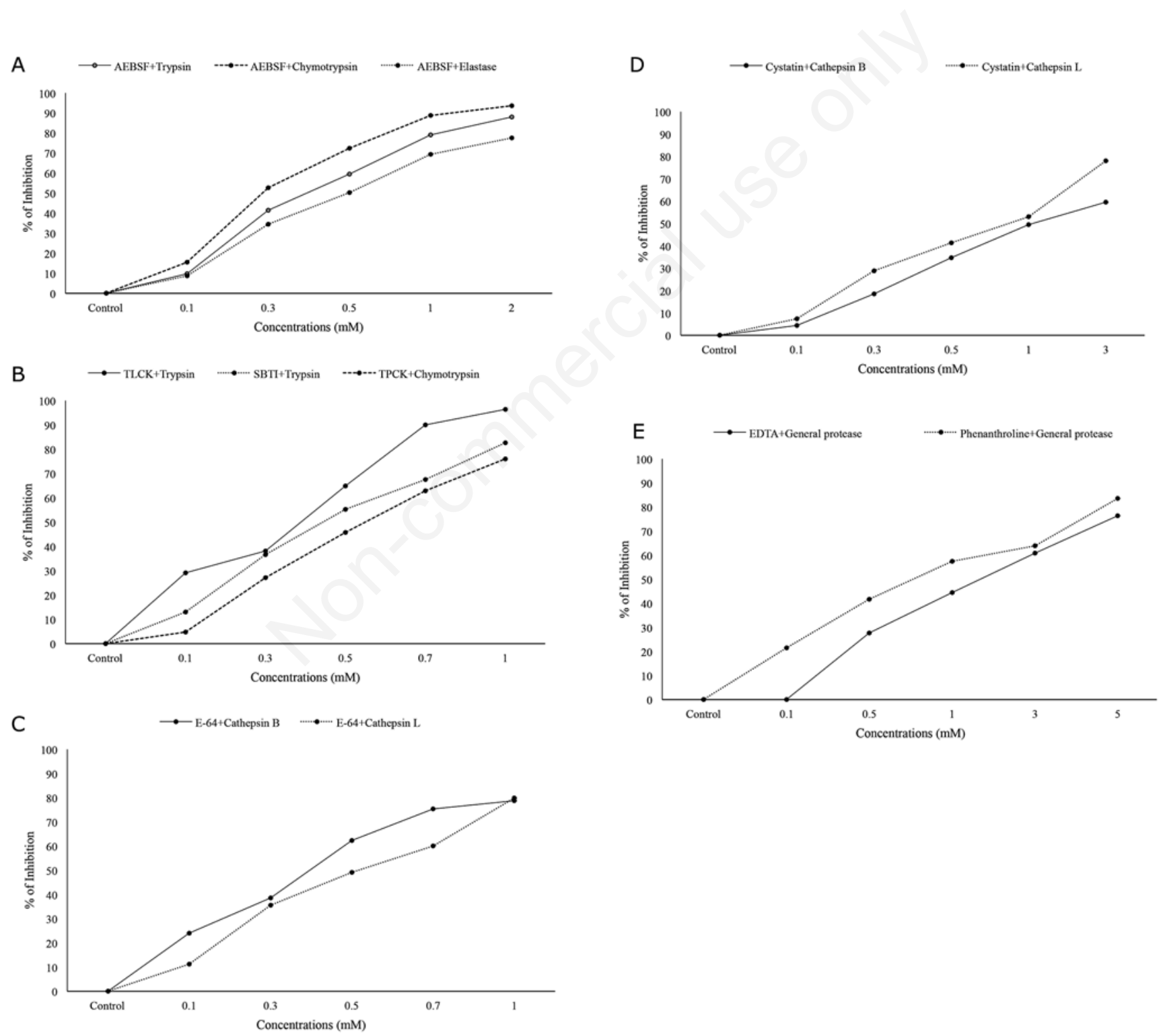

Figure 7. Specific inhibitors on proteolytic activities in the larval midgut of $D$. palidata using specific substrates. A) Effect of AEBSF on trypsin, chymotrypsin and elastase activities. B) Effects of TLCK, SBTI and TPCK on trypsin and chymotrypsin activities. C) Effect of E-64 on cathepsins B and L. D) Effect of cystatin on cathepsins B and L. E) Effects of EDTA and phenanthroline on general proteolytic activity. 
feedback of the program. In such a condition, insects produce inhibitorsensitive proteinases or novel inhibitor-insensitive proteinases. Feeding and survival assays using synthetic inhibitors or different lectins may clarify our supposition regarding the proteolytic profile in $D$. palidata.

\section{References}

AJAMHASSANI M., ZIBAEE A., SENDI J.J., ASKARY H., FARRAR N., 2012 - Proteolytic activity in the midgut of the Crimson speckled moth, Utethesia pulchella L. (Lepidoptera: Arctiidae). - J. Plant. Prot. Res 52: $368-373$.

ANKRI S., MIRELMAN D., 1999 - Antimicrobial properties of allicin from garlic. - Microb. Infec. 2: 125-129.

CLEMENT F., PRAMOD S.N., VENKATESH Y.P., 2010 - Identity of the immunomodulatory proteins from garlic (Allium sativum) with the major garlic lectins or agglutinins. - Inter. Immunopharmacol. 10: 316-324.

CRISTOFOLETTI P.T., RIBEIRO A.F., DERAISON C., RAHBE Y., TERRA W.R., 2003. -Midgut adaptation and digestive enzyme distribution in a phloem feeding insect, the pea aphid Acyrthosiphon pisum. - J. Insect. Physiol. 49: 11-24.

DELKASH-ROUDSARI S., ZIBAEE A., ABBCI-MOZHDEHI M.R., 2014. Digestive proteolytic activity in larvae and adults of Bactrocera oleae Gmelin (Diptera: Tephritidae). - J. Asia-Pacific. Entomol. 17: 483-491.

ELPIDINA E.N., VINOKUROV K.S., GROMENKO V.A., RUDENSKAYA Y.A., DUNAEVSKY Y.E., ZHUZHIKOV D.P., 2001 Compartmentalisation of proteinases and amylases in Nauphoeta cinerea midgut. - Arch. Insect. Biochem. Physiol. 48: 206-216.

FERREIRA C., TERRA W.R., 1983 - Physical and kinetic properties of a plasma-membrane-bound P-Dglucosidase (cellobiase) from midgut cells of an insect (Rhynchosciara americana larva). - Biochem. J. 213: 43-51.

GARCIA-CARRENO F.L., DIMES L.E., HAARD N.F., 1993 - Substrate-gel electrophoresis for composition and molecular weight of proteinases or proteinaceous protease inhibitors. - Analyt. Biochem. 214: 61-69.

HAHM B., HAN D.S., BACK S.H., SONG 0.K., CHO M.J., KIM C.J., 1995 - NS3-4A of hepatitis C virus is a chymotrypsin-like protease. - J. Virol. 69: 2534-9.

HAMADA M., KAWANO E., KAWAMURA S., 1981 - Radiation- and photoinduced degradation of five isomers of 1,2,3,4,5,6-hexachlorocyclohexane. - Agri. Biol. Chem. 45: 659-665.

HAYDARI H., 1986 - Bioecology of Dyspessa palidata in Hamedan. - J. Plant. Pest. Disease. 54: 1-9.

JOHNSON K.S., RABOSKY D., 2000 - Phylogenetic distribution of cysteine proteinases in beetles: evidence for an evolutionary shift to an alkaline digestive strategy in Cerambycidae. - Comp. Biochem. Physiol B. 126: 609-619.

KANOST M.R., CLEM R.J., 2012 - Insect proteases. In: GILBERT L.I (ed.), Insect molecular biology and biochemistry. - Elsevier B.V., San Diego, pp. 346-364.

KHANJANI M., 2005 - Pests of vegetables. - Bu'ali Sina University Press, 719 pp.

LAEMMLI U.K., 1970 - Cleavage of structural proteins during the assembly of the head of bacteriophage T4. Nature. 227: 680-685.

LEHANE M.J., BULLER H.M., CRISANTI A., 1996 - Mechanisms controlling the synthesis and secretion of digestive enzymes in insects. In: LEHANE M.J., BILLINGSLEY P.F., (eds.), Biology of the insect midgut. - Chapman \& Hall, London, pp 195-205.

LOWRY 0.H., ROSEBROUGH N.J., FARR A.L., RANDALL R.J., 1951 Protein measurement with the Folin phenol reagent. - J. Biol. Chem. 193: 265-275.

OPPERT B., 2000 - Transgenic plants expressing enzyme inhibitors and the prospects for biopesticide development. In: KOUL 0., DHALIWAL G.S. (eds.), Phytochemical biopesticides. - The Netherlands, Harwood Academic, pp. 83-95.

RANJBAR M., SENDI J.J., ZIBAEE A., 2011 - Proteolytic activity in the midgut of Ectomyelois ceratoniae Zeller (Lepidoptera: Pyralidae), Pomegranate carob moth. - Invert. Surv. J. 8: 132-142.

SAIKIA M., SINGH Y.T., BHATTACHARYA A., MAZUMDAR-LEIGHTON S., 2011 - Expression of diverse midgut serine proteinases in the sericigenous Lepidoptera Antheraea assamensis (Helfer) is influenced by choice of host plant species. - Insect. Mol. Biol. 20: 1-13.

SHAW E., MARES-GUIA M., COHEN W., 1965 - Evidence for an activecenter histidine in trypsin through use of a specific reagent 1chloro-3-tosylamido-7-amino-2-heptanona, the chloromethyl ketone derived from N- $\alpha$-tosyl--lysine. - Biochem. 4: 2219-24.

TERRA W.R., FERREIRA C., 1994 - Insect digestive enzymes: properties, compartmentalization and function. - Comp. Biochem. Physiol B. 109: 1-62.

TERRA W.R., FERREIRA C., 2012 - Biochemistry and moelcular biology of digestion. In: GILBERT L.I. (ed.), Insect molecular biology and biochemistry. - Elsevier B.V., San Diego, pp 365-418.

WALSMANN P., RICHTER M., MARKWARDT F., 1972 - Inactivation of trypsin and thrombin by 4-amidinobenzolsulfofluoride and 4-(2aminoethyl)-benzolsulfofluoride. - Acta. Biol. Med. Ger. 28: 577-585.

WOODRING J., DIERSCH S., IWALABA D., HOFFMANN K.H., MEYERING-VOS M., 2009 - Control of the release of digestive enzymes in the caeca of the cricket Gryllus bimaculatus. - Physiol. Entomol. 34:144-151.

YAZDANI E., ZIBAEE A., SENDI J.J., 2013. - Digestive proteases of Papilio demoleus L. (Lepidoptera: Papilionidae): compartmentalization and characterization. - Phytopara. 42: 121-133.

ZIBAEE A., 2012 - Digestive enzymes of large cabbage white butterfly, Pieris brassicae L. (Lepidoptera: Pieridae) from developmental and site of activity perspectives. - Ital. J. Zool. 79: 13-26. 